\title{
SHORT COMMUNICATION: MUTUAL OLFACTORY RELATIONSHIPS IN RABBITS RAISED IN INDIVIDUAL CAGES
}

\author{
Negretti P.", Bianconi G. ", Finzi A.., \\ *Department of Animal Production, University of Tuscia. 01100 Viterbo. Italy. \\ †Rabbit Unconventional Rearing Centre. Consorzio ‘Coniglio Verde’. Via S. Maria 43. 01030 Vasanello. Italy.
}

\begin{abstract}
Авstract: A set of three contiguous cages was utilised to test the possibility that rabbits establish sniffing relationships when housed in contiguous cages as occurs on farms. The single cages were separated by a tin divider slide in which very small holes were made. This system allows the smell to be sensed while a visual relationship was not possible. The experimental set was then located in an open air shed under a roof with no walls, in order to allow olfactory stimuli and to make it possible to perceive its direction and possibly its origin. This set-up avoided the odours saturating the environment so that the animals could sense each other's presence. Three 16 wk old does were housed in contiguous cages at the same time. The animals were video-recorded at one frame per minute for 8 consecutive days and a total of 11,500 frames per animal were recorded. The trial was replicated under the same conditions with three new does. Progressively decreasing sniffing behaviour $(P<0.001)$ was observed. The behaviour of all the does in the lateral cages was similar and there were no significant differences. Frequent reciprocal sniffing was also observed, mainly in the first few days. The results indicate that a sniffing relationship is established among rabbits but this behaviour decreases rapidly. It is possible that after the initial interest shown, rabbits do not show any specific behavioural changes when sensing other animals.
\end{abstract}

Key Words: rabbits, farm cages, sniffing, social behaviour.

\section{INTRODUCTION}

On commercial rabbit farms, bucks and does are normally kept in single cages. The possible deprivation of social relationships in single cages has been considered as an important factor impairing animal welfare and it has been suggested that suitable quarters for rabbits should allow for social interaction (Verga, 2000; Trocino and Xiccato, 2006; Jordan et al., 2007). According to Boers et al. (2002) and López (2002), rabbits should always be housed in such a way that they can maintain visual contact with the group. In earlier studies Negretti et al. (2008) obtained evidence that a mutual visual relationship is established between subjects housed in contiguous cages and this was considered as a factor that reduced social deprivation to a certain extent. To further this line of research it was considered that a relationship between animals could also be established by smelling (Boers et al., 2002). Therefore, the aim of this work was to discriminate sight from smelling as a way of establishing a social relationship.

Correspondence: A. Finzi, finzi@unitus.it

Received June 2009 - Accepted December 2009 


\section{MATERIALS AND METHODS}

The same set of three contiguous cages utilised to test the visual relationships (Negretti et al., 2008) was used in the study. However, the single cages were separated by a tin slide in which very small holes, of pin dimension $(1.5 \mathrm{~mm})$, were made in order to permit odours to be sensed but not a visual relationship. Holes were arranged in 4 rows, 7 holes per row, at a distance of $6 \mathrm{~cm}$ from each other, both vertically and horizontally. After some early trials, it was decided that a closed environment was not suitable for such an experiment, since odours may accumulate in the environment and hence animals could sense each other's presence without any specific behavioural change that could show mutual interest by smelling.

The experimental cages were therefore located in the open air under a roof and no side walls, in order to permit the dispersion of the olfactory stimuli and make it possible to perceive the direction of origin. The hypothesis was that the rabbits on both sides (A and $\mathrm{C}$ ) would show an interest toward the rabbit in the central cage, while this one (B) could show no preference or a specific preference for either of the two rabbits housed in the lateral cages.

Three 16 wk old does were housed in contiguous cages at the same time. The animals were video-recorded for 8 consecutive days. Recording was programmed to take one frame per minute leading to a total of 11,500 shots per animal. The use of infrared light made it possible to record the rabbits' behaviour day and night. The occurrences were considered separately when a single doe was sniffing by the tin wall (Figure 1) or when they were both sniffing at each other. The trial was replicated with three new does under the same conditions.

\section{Statistical Analysis}

In order to analyze the change over the time in the occurrences of i) rabbits putting their nose near to the tin wall, or ii) reciprocal sniffing contact, Pearson's $\chi^{2}$ contingency tables and the standardized residuals (R) were calculated. In the interpretation of the standardized residuals 1.96 was the discriminating value for a confidence level of $95 \%$. In order to analyze the consistence of these behaviours among individuals, median tests were performed. In order to analyze the differences between the number of times the rabbit in the central cage put its nose against the solid walls on both sides, a Kolmogorov-Smirnoff test was performed. These analyses (Ferrán, 1996) were performed using SPSS 9.0 (SPSS Inc., 1999).

\section{RESULTS AND DISCUSSION}

When rabbits were located in the lateral cages (A and C), the frequency of each subject putting its muzzle at the tin wall decreased regularly day after day (Figure 2 a). This type of behaviour was shown by

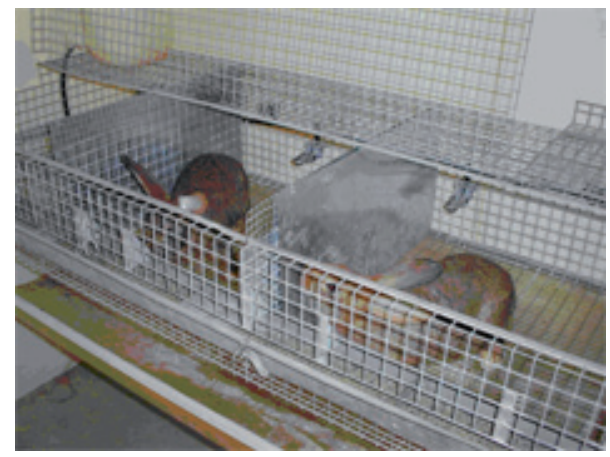

Figure 1: Two examples of sniffing at the tin wall.

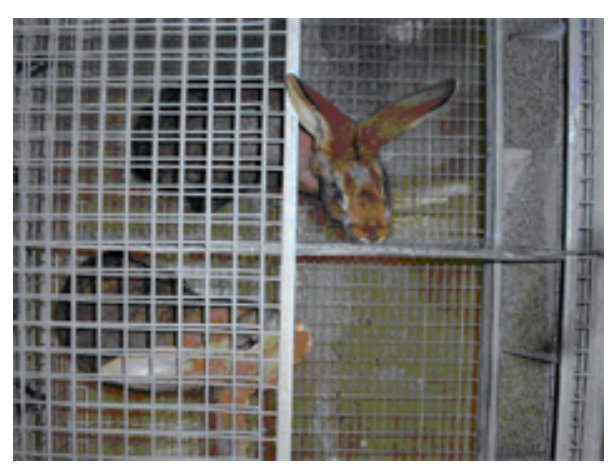



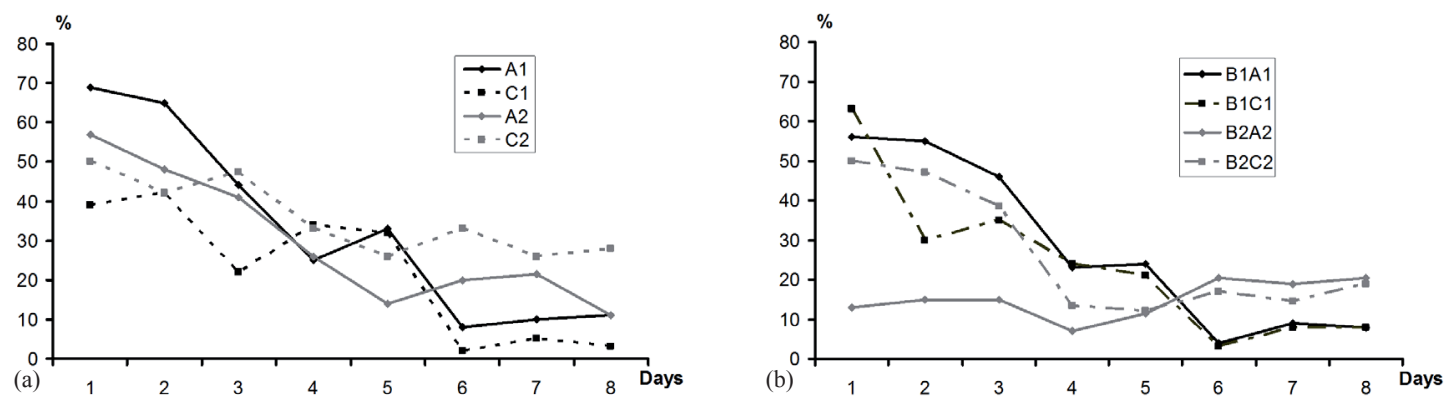

Figure 2: Percentage of occurrences of rabbits putting their nose near to the tin wall on consecutive days, in the first and second trial (1 and 2): (a) when the animals are located in the lateral cages (A and C); (b) of does located in the central cage (B) towards the does at both sides (A and B).

all subjects and was very consistent $(P<0.001)$ confirming that behavioural tests should be continued for many days to allow a reliable interpretation. In fact, behaviour can be different between the test animals and, furthermore, an individual's behaviour can also change over time (Finzi et al., 1997; Margarit and Finzi, 2000; Negretti et al., 2004; 2008).

The subject B1, in the central cage (Figure $2 \mathrm{~b}$ ), put its nose against the solid walls on both sides of the cage nearly the same number of times. The frequency of that behaviour was thus about twice that of the subjects housed in the lateral cages. The

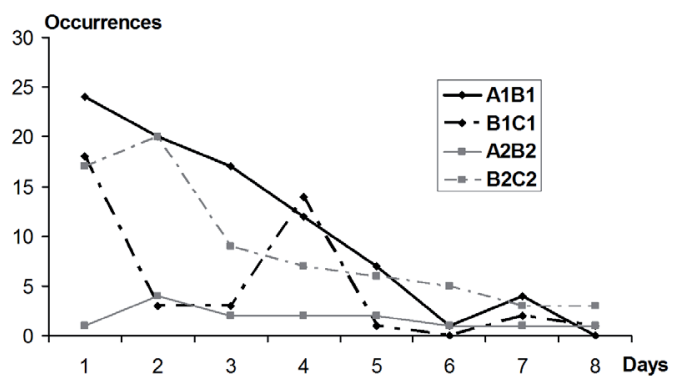

Figure 3: Number of occurrences of reciprocal sniffing contact, nose to nose, through the tin wall on consecutive days. decreasing trends were similar and the observed differences between them were small and not significant. The subject B2, showed similar behaviour to subject $\mathrm{B} 1$ only towards the subject $\mathrm{C} 2$, appearing not to be interested in sensing the presence of the doe located on the opposite side. This could indicate possible individual preferences through sniffing behaviour similarly to the way they do through visual behaviour (Negretti et al., 2008).

These results were interpreted as animals showing an initial interest to identify the rabbits in the nearby cages by smell, but this did not last over time. Rabbits could detect the smell without directing their heads towards the source, since the smell reached them anyway. So, in this situation, there was no need for any specific behaviour. This was distinguished from the behaviour observed in a visual relationship that remained constant all the time (Negretti et al., 2008).

When only the occurrences of reciprocal contemporary sniffing were considered (Figure 3 ) the values appeared surprisingly high being about $1 / 3$ of the total sniffing at the wall. Though the trend of occurrences in the relationship was irregular (individuality), the frequencies still decreased rapidly, confirming the hypothesis that a social relationship can be made and maintained by sniffing when rabbits are housed in single cages. The rare reciprocal sniffing between B2 and A2 depended on the lack of interest in the subject B2 as shown in Figure 3.

It is possible that listening behaviour could also be involved, but the idea was discarded since no specific orienting of the rabbits' ears was observed and previous research has shown that hearing is mainly related to short lasting alarm behaviour (Finzi et al., 1986). 


\section{CONCLUSIONS}

In conclusion, the results show that a social relationship among rabbits housed in contiguous case could be established by sniffing. Although specific sniffing seems to be no longer necessary when the rabbits have identified each other.

\section{REFERENCES}

Boers K., Gray G., Love J., Mahmutovic Z., McCormick S., Turcotte N., Zhang Y. 2002. Comfortable Quarters for Rabbits in Research Institutions. Comfortable Quarters for Laboratory Animals. Animal Welfare Institute, Washington, DC (U.S.A.).

Ferrán M. 1996. SPSS para Windows 95. Programación y análisis estadístico. McGraw-Hill, Madrid, Spain.

Finzi A., Valentini A., Verità P. 1986. Fattori di stress nel coniglio. Coniglicoltura, 23: 50-51.

Finzi A., Margarit R., Calabrese A. 1997. Une cage à 2 étages pour le bien-être des lapins. Cuniculture 24: 159-161.

Jordan D., Kermauner A., Štuhec I. 2007. Il comportamento dei conigli all'ingrasso. Coniglicoltura, 5: 30-34.

López M. 2002. ¿Donde estamos en esto del bienestar?. In Proc.: XXVII Symposium de ASESCU. 29-31 March, 2002. Reus, Spain. 191-204.

Margarit R., Finzi A. 2000. Setting of feeders, waterers and nest-boxes in two-floor cages for animal welfare. In Proc.: $7^{\text {th }}$ World Rabbit Congress, 4-7 July, 2000, Valencia, Spain. Vol. B, 553-557.
Negretti P., Albani A., Finzi A. 2004. Location and social behaviour of young rabbits bucks. In Proc.: $8^{\text {th }}$ World Rabbit Congress, 7-10 September, 2004. Puebla, Mexico. 1257-1263.

Negretti P., Bianconi G., Finzi A. 2008. Mutual visual relationships of rabbits raised in individual cages. In Proc.: $9^{\text {th }}$ World Rabbit Congress, 10-13 June, 2008. Verona, Italy. 1213-1216.

SPSS. 1999. SPSS 9.0. Manual del usuario. SPSS Inc., Chicago, USA.

Verga M. 2000. Intensive rabbit breeding and welfare: development of research, trends and applications. In Proc.: $7^{\text {th }}$ World Rabbit Congress, 4-7 July, 2000, Valencia, Spain. Vol. 491-509.

Trocino A., Xiccato G. 2006. Animal welfare in reared rabbits: a review with emphasis on housing systems. World Rabbit Sci., 14: 77-93. 